\title{
Stage IV Cervical Cancer AJCC v8
}

National Cancer Institute

\section{Source}

National Cancer Institute. Stage IV Cervical Cancer A/CC v8. NCI Thesaurus. Code C139753.

Stage IV includes: IVA: T4, Any N, M0; IVB: Any T, Any N, M1. T4: T umor invading the mucosa of the bladder or rectum, and/or extending beyond the true pelvis (bullous edema is not sufficient to classify a tumor as T4). M0: No distant metastasis. M1:

Distant metastasis (including peritoneal spread or involvement of the supraclavicular, mediastinal, or distant lymph nodes; lung; liver; or bone). (from AJCC 8th Ed.) 